\title{
APPLICATION OF UNMANNED AERIAL VEHICLES IN DETERMINING THE CUBIC CONTENTS OF MATERIAL
}

\author{
Stefan Miljković ${ }^{1}$ \\ Miroslav Kuburić ${ }^{2}$ \\ Vukan Ogrizović ${ }^{3}$ \\ Siniša Delčev ${ }^{4}$ \\ Jelena Gučević
}

UDK: 623.746.2:528.02

DOI:10.14415/konferencijaGFS2017.095

Summary: Determination of cubature of construction or some other material is important from different aspects - the financial aspect being the most important. Calculation of these cubages was most commonly done on the basis of geodetic survey with conventional instruments. The emergence of unmanned aircrafts made possible for surveying of different types of materials to be done very quickly and efficiently and with satisfactory accuracy. The paper will present the use of unmanned aerial vehicles for calculating cubatures on an example of landfills, surveyed in a number of series.

Keywords: Unmanned Aerial Vehicle, calculation of volumes, digital terrain model

\section{INTRODUCTION}

Conventional geodetic survey techniques become more and more replaceable by new technologies. This is also the case with surveying of different types of landfills, piles and building materials. This material is used in carrying out the most different types of construction works and it is very important to determine the exact quantity of used materials as this is a basis for calculation i.e. billing for the work done. When applying conventional surveying techniques, it is very important for a geodetic expert to have appropriate experience in surveying landfills. This is because landfill volumes are determined on the basis of characteristic points and if a geodetic expert is not experienced, it can happen very easily that wrong values of volumes are obtained. Apart from the experts, a surveying team is made of at least one more member, a 'rod man', who sets an

\footnotetext{
${ }^{1}$ Stefan Miljković, master in geodesy, B.Sc., Belgrade University, Faculty of Civil Engineering, Bul. kralja Aleksandra 73, Belgrade, Serbia, phone: +381 64 4031006, e-mail: skiljk@live.com

${ }^{2}$ Miroslav Kuburić, graduate geodetic engineer, Novi Sad University, Faculty of Civil Engineering in Subotica, Kozaračka 2a, Subotica, Srbija, phone: +381 24554 300, e-mail: mkuburic@gf.uns.ac.rs

${ }^{3}$ Vukan Ogrizović, graduate geodetic engineer., Belgrade University, Faculty of Civil Engineering, Bul. kralja Aleksandra 73, Belgrade, Serbia, phone: +381 113218 582, e-mail: vukan@grf.bg.ac.rs.

${ }^{4}$ Siniša Delčev, graduate geodetic engineer, Belgrade University, Faculty of Civil Engineering, Bul. kralja Aleksandra 73, Belgrade, Serbia, phone: +381 113218 542, e-mail: delcev@ grf.bg.ac.rs.

Jelena Gučević, graduate geodetic engineer, Belgrade University, Faculty of Civil Engineering, Bul. kralja Aleksandra 73, Belgrade, Serbia, phone: +381 113218 542, e-mail: gucevic@ grf.bg.ac.rs.
} 
appropriate signal (prism) on characteristic points of the landfill, naturally, according to the experts' instruction.

The emergence of Unmanned Aerial Vehicles - UAVs made possible the entire process of surveying landfills to be automated, as well as reducing the time necessary for surveying. In doing so, the obtained results are of the same or even better accuracy, compared to the application of conventional techniques. Automation is first of all reflected in creating the landfill model, but also in the manner of collecting data - the entire process is highly automated and is done with insignificant interventions by the experts. Consequently, the time necessary to determine the landfill cubage is shortened.

\section{APPLICATION OF UAVS FOR PHOTOGRAMMETRY}

The emergence of UAVs and their application for photogrammetric surveys opens up a wide array of possibilities and applications in different engineering and technical fields (geodesy, civil engineering, geology, etc.) The data obtained by this method are very suitable both for visual and metric analyses of spatial phenomena, reliefs, land masses, vegetation, etc.

With an advance of technology, UAVs have seen a big expansion in recent years in terms of autonomy, type and quality of sensors that they carry. Hence the constant progress of the volume and quality of data that are obtained by their use. The degree of works automation is at a very high level.

The main advantage of UAV photogrammetry compared to conventional aerial photogrammetry is in the fact that UAV can also be used in risky situations without jeopardizing human lives, as well as in inaccessible area, at low flight heights as well as at the flights that are close to the objects in which the conventional aerial photogrammetry is impossible to use. UAVs are incomparably more economical compared to conventional airplanes; therefore their application is much more cost-effective on smaller objects and projects.

Nowadays, UAV represents a precise, automated and computer-controlled method for collection of geo-spatial data.

\subsection{Types and division of UAVs}

From the point of view of technical characteristics of unmanned vehicles, categorization may be done into: aircrafts with and without supply, crafts with flexible, fixed and rotational wings. In addition to this, there are many other divisions and categorization of UAVs according to the purpose, size, maximum flight height, maximum range, etc.

Aircrafts most commonly used for photogrammetry surveys are those with fixed wings (aircrafts) and aircrafts with rotating wings (helicopters or multirotors); on the other hand, the balloons (airships) filled with helium or some other chemical substance are also often used (Figure 1).

Specialized aircrafts the main purpose of which is mapping and collecting spatial data can be found in the market. Some of the better known companies that deal with the production of such crafts include Trimble, Sensefly and Leica Geosystem. In addition to specialized 
Contemporary achievements in civil engineering 21. April 2017. Subotica, SERBIA

UA, universal crafts of Company DJI and the like can also be used for the needs of photogrammetry.

a)

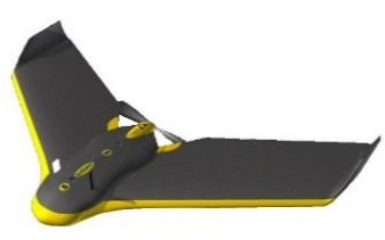

b)

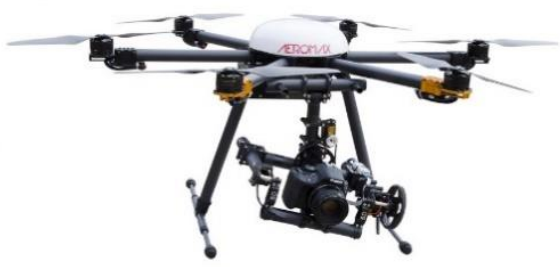

c)

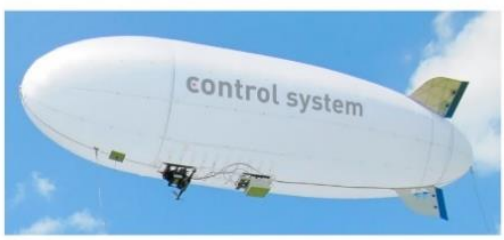

Figure 1: Types of UAVs used for photogrammetry: a) airplane, b) multirotor and c) airship (zeppelin)

\subsection{Basics of photogrammetric survey}

Photogrammetry is a technique of displaying and measuring 3D objects with the help of the data stored on 2D photographs. A photograph is an image that originated from projecting any point of the object on the film or digital sensor. Like any other type of projection, a photograph does not contain enough information for full overview of a certain space. The main reason for that is that each light beam contains infinitely many points, and therefore, the three-dimensional space on photographs is reduced to two dimensions. At least two projections are necessary to obtain spatial coordinates of points, i.e. a 3D model can be constructed on the basis of 2 photographs of the same object.

It will never happen in practice that only two shots are used. It is necessary to collect many more shots (images) to cover the entire concerned surface and enable establishing connections between shots. It is also necessary to ensure appropriate longitudinal and traverse overlap between the shots (each part of the field surface must be found on at least two shots).

\section{APPLICATION OF UAVS FOR CALCULATION OF CUBATURE OF GRAVEL DUMP}

With the application of UAV photogrammetry a digital model of the terrain and Orthophoto plan are obtained. The digital model of the terrain is very suitable for calculation of cubatures of land masses. 
In this paper we present the calculation of cubature for material (gravel) piles on construction material dumps with an overview of the repeatability of the results. Independent surveying with UAV photograph was done on two independent landfills in three surveying epochs, during the time interval of six months each.

One pile was separated on each landfill for which it was found that there were no changes of volumes between the epochs (Figure 2). Cubatures of the piles were calculated in all epochs in order to present the level of repeatability of results.
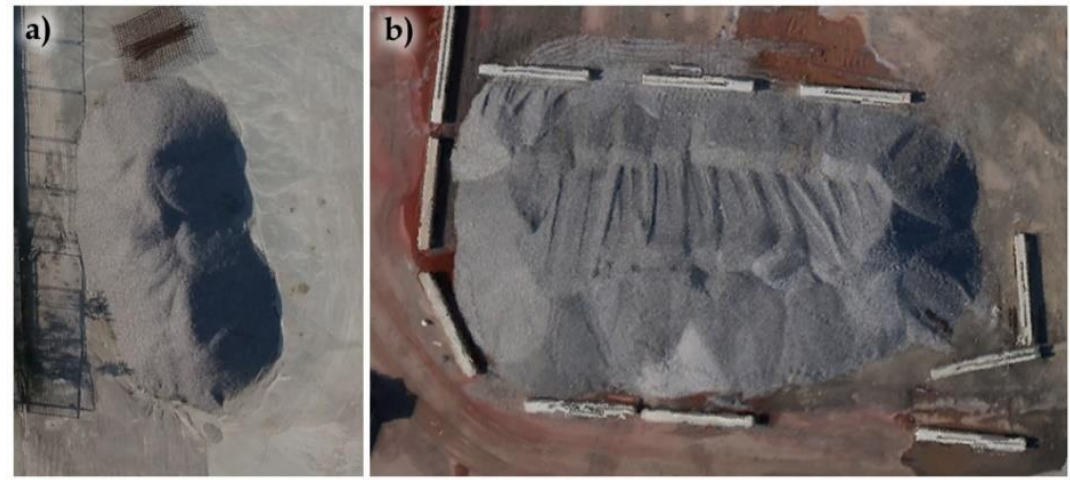

Figure 2: Piles that are subject to experiment

\subsection{Surveying parameters and processing the measuring results}

Measurements were done by UAV branded as Skywalker X8. The weight of the craft is 2.5 $\mathrm{kg}$, while a wing span is $2.2 \mathrm{~m}$ (Figure 3 ). The camera that the craft has is Sony NEX $5 R$, the size of the sensor $23.7 \mathrm{~mm} \times 15.6 \mathrm{~mm}$, sensor resolution is $4912 \times 3264$ pixels, the focal length is $16 \mathrm{~mm}$.

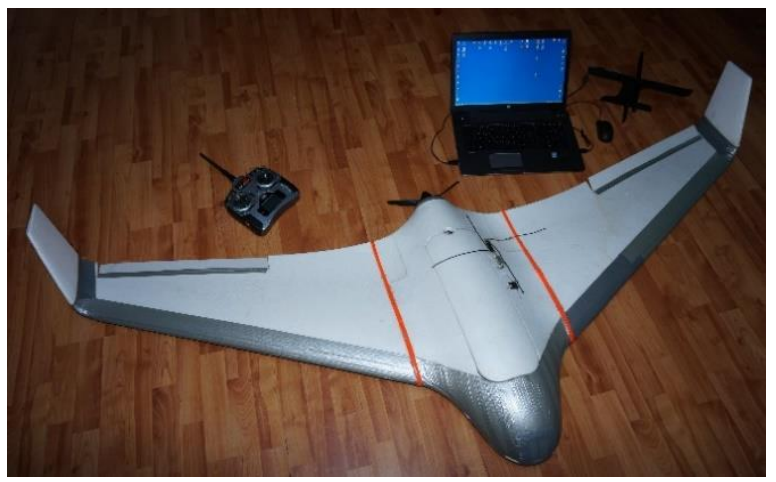

Figure 3: Skywalker X8 with accessories

The main parameters of surveying are presented in Table 1, while their practical meaning is presented in Figure 4. 


\section{$5^{\text {th }}$ INTERNATIONAL CONFERENCE}

Contemporary achievements in civil engineering 21. April 2017. Subotica, SERBIA

Before surveying the field, signal markers were stabilized representing, at the processing stage, orientation points based on which self-calibration of camera was done and referencing of the terrain model. An optimum number of orientation points were set with approximately the same layout in all surveying epochs. The coordinates of orientation points are obtained by GPS measurements in RTK mode so that each point was measured in three repetitions, 30 seconds each.

Table 1: The main surveying parameters and their values

\begin{tabular}{|c|c|}
\hline Parameter & Value \\
\hline Flight height (h) & $100 \mathrm{~m}$ \\
\hline Surveying scale & 6250 \\
\hline Pixel size in nature & $30.2 \mathrm{~mm}$ \\
\hline Sensor size in nature (S x L) & $98 \times 148 \mathrm{~m}$ \\
\hline Longitudinal overlap & $75 \%$ \\
\hline Surveying base (B) & $24.5 \mathrm{~m}$ \\
\hline Transverse overlap & $60 \%$ \\
\hline Distance between strings (A) & $29 \mathrm{~m}$ \\
\hline
\end{tabular}

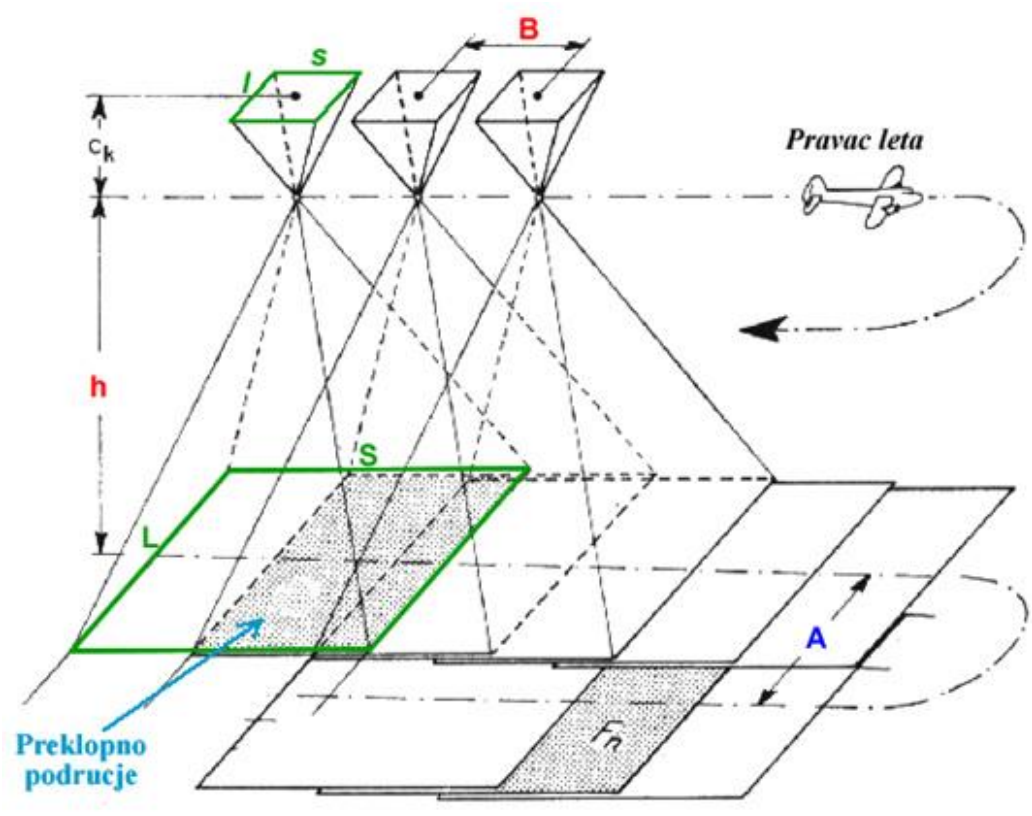

Figure 4: Surveying parameters

The obtained scans in all surveying epochs were processed in software Agisoft PhotoScan. Leveling of the model, self-calibration of camera, generating the point cloud, orthophoto 
Савремена достигнућа у грађевинарству 21. април 2017. Суботица, СРБИЈА

and digital altitude model were carried out by the same software. 3D accuracy of leveling the model is $\leq 6 \mathrm{~cm}$, which is as expected.

\subsection{Results of the experiment}

Digital elevation models (DEMs) were generated in software Agisoft PhotoScan for each pile in every measurement epoch. For each pile a DEM was made of the surface of the pile as well as a DEM of the bottom of pile, which was obtained by interpolation of the surrounding ground once that the pile is cut (Figure 5). The digital elevations models were exported as a raster form in .tiff format.
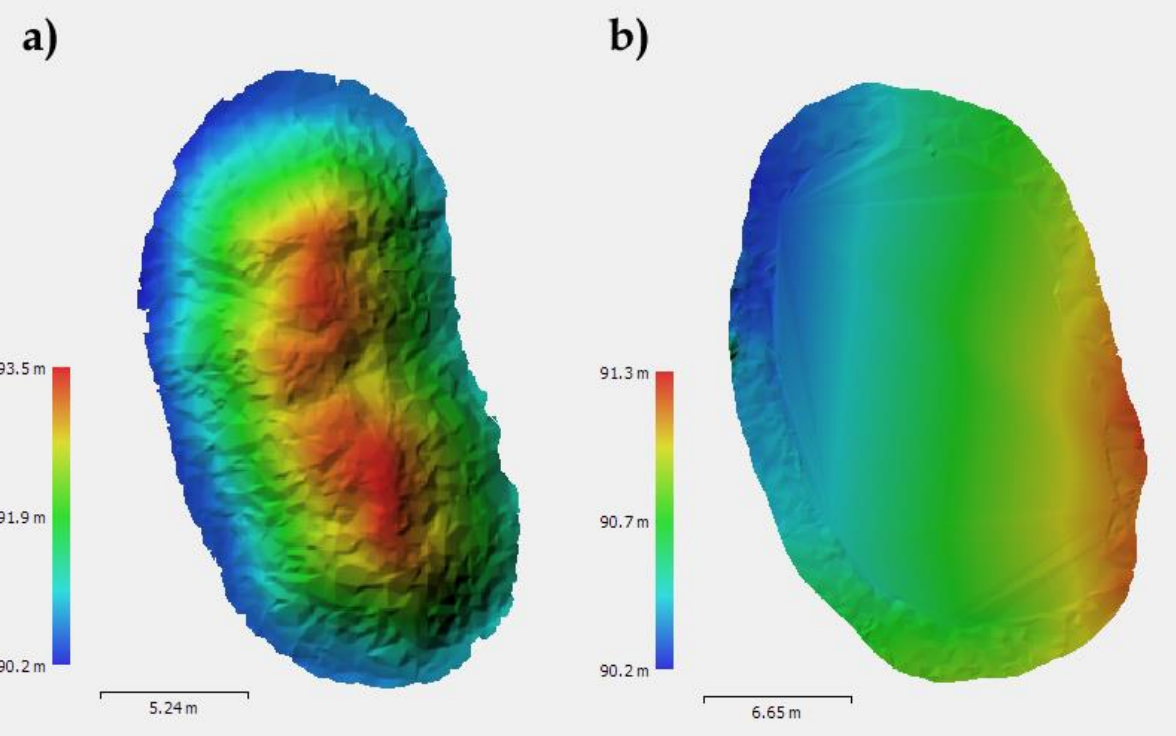

Figure 5: DEM piles ( a) DEM of the upper surface of the pile, b) DEM of the bottom of the pile

Calculation of cubic contents was done in Global Mapper software. Calculated cubatures at all epochs and their differences are presented in Table 2.

Table 2: Calculated cubic contents

\begin{tabular}{|c|c|c|c|c|c|c|}
\hline & \multicolumn{3}{|c|}{ Cubic contents } & \multicolumn{3}{c|}{ Differences } \\
\cline { 2 - 7 } & Epoch 1 & Epoch 2 & Epoch 3 & E2 - E1 & E2 - E3 & E3 - E1 \\
\hline \multirow{2}{*}{ Pile 1 } & \multirow{2}{*}{$1033 \mathrm{~m}^{3}$} & $1071 \mathrm{~m}^{3}$ & $1045 \mathrm{~m}^{3}$ & $\begin{array}{c}38 \mathrm{~m}^{3} \\
3.55 \%\end{array}$ & $\begin{array}{c}26 \mathrm{~m}^{3} \\
2.43 \%\end{array}$ & $\begin{array}{c}12 \mathrm{~m}^{3} \\
1.15 \%\end{array}$ \\
\hline
\end{tabular}


Contemporary achievements in civil engineering 21. April 2017. Subotica, SERBIA

\begin{tabular}{|c|c|c|c|c|c|c|} 
Pile 2 & $266 \mathrm{~m}^{3}$ & $270 \mathrm{~m}^{3}$ & $275 \mathrm{~m}^{3}$ & $4 \mathrm{~m}^{3}$ & $5 \mathrm{~m}^{3}$ & $9 \mathrm{~m}^{3}$ \\
& & & $1.48 \%$ & $1.79 \%$ & $3.23 \%$ \\
\hline
\end{tabular}

\section{CONCLUSION}

Unmanned vehicles have been increasingly suppressing the conventional surveying methods and find application in solving different geodetic problems. One of more and more frequently used applications of these crafts is in surveying landfills and determination of their cubic volume. The advantage of these crafts over conventional methods is multiple, and the most important ones are almost full automation and speed of surveying. In that, cubic contents may be determined with appropriate accuracy and satisfactory repeatability. This paper presents the application of unmanned vehicles in determining cubic volumes of gravel dumps. From the results obtained from surveying these dumps over a number of time epochs, it was proved that this method had a big result repeatability, which means that it may also be considered as a very reliable method for determining cubatures.

\section{REFERENCES}

[1] F. Remondino, L. Barazzetti, F. Nex, M. Scaioni, D. Sarazzi: UAV PHOTOGRAMMETRY FOR MAPPING AND 3D MODELING - CURRENT STATUS AND FUTURE PERSPECTIVES -, International Archives of the Photogrammetry, Remote Sensing and Spatial Information Sciences, Vol. 38(1/C22), Zurich, Switzerland. 2011.

[2] Henri Eisenbeiß: UAV Photogrammetry, ETH ZURICH, 2009, ISSN 0252-9335

[3] J.A. Gonçalvesa, R. Henriquesc: UAV photogrammetry for topographic monitoring of coastal areas, ISPRS Journal of Photogrammetry and Remote Sensing, Volume 104, June 2015, Pages 101-111.

[4] K. Kraus: Photogrammetrie (Fotogrametrija); Osnove i standardni postupci [Basics and Standard Procedures], Institut for Photogrammetry of the Techncial Faculty in Vienna, 1985.

[5] Li Z, Zhu Q, Gold C. DIGITAL TERRAIN MODELING Principles and Methodology. Florida: CRC Press. 318 str., 2005.

[6] Ryan Johnny C., Hubbard Alun Lloyd, Box Jason E., Todd Joe, Christoffersen Poul, Carr J. Rachel, Holt Tom O., Snooke Neal A.: UAV photogrammetry and structure from motion to assess calving dynamics at Store Glacier, a large outlet draining the Greenland ice sheet, The Cryosphere, 9, 1-11, 2015.

[7] W. Linder: Digital Photogrammetry; A Practical Course, University of Düsseldorf Department of Geography, 2005.

[8] www.agisoft.com - Agisoft official website

[9] www.bluemarblegeo.com/products/global-mapper.php - Global Mapper oficijalni sajt. 